\title{
A Comparison between Personality Traits and Defense Styles in Teenagers with Avoidant Restrictive Food Intake Disorder and Normal Individuals
}

\author{
Narges Zamani ${ }^{1}$, Mojtaba Habibi ${ }^{2}$, Nasrin Zamani ${ }^{3}$, \\ Nina Jamshidnejad², Mani B. Monajemi ${ }^{4}$
}

\section{ABSTRACT}

Objective: The current study aims to compare the defense mechanisms and personality traits among teenagers with avoidant restrictive food intake disorder (ARFID) and normal individuals. Materials and Methods: Incurrent casual-comparative study, 220 teenagers with an average age of 16.74 \pm 6.08 and age range of 13-17 were randomly selected from among high school students, who were diagnosed with avoidant restrictive food intake disorder in fall 2014 and 220 other peers with matching demographic characteristics were selected as the control group. Both groups were asked to fill Eysenckpersonality questionnaire and Andrews’ Defense Style Questionnaire. Data was analyzed via multivariate analysis of variance.

Results: The average scores of teenagers with ARFID was higher than the control group regarding immature and neurotic defense style, neuroticism and extraversion; with respect to mature defense style variable average scores of teenagers with ARFID was lower comparing to control group. Thus, it can be concluded that there is a significant difference between personality traits and defence styles of teenagers with ARFID and normal teenagers.

Keywords: Personality Traits, Defense Styles, Avoidant Restrictive Food Intake Disorder (ARFID)

Avoidant Restrictive Food Intake Disorder (ARFID), which was added by American Psychiatric Association to Diagnostic and Statistical Manual of Mental Disorders $5^{\text {th }}$ edition (DSM-V, 2013) as a new diagnostic measure, was known as feeding and eating disorders in Diagnostic and Statistical Manual of Mental Disorders, $4^{\text {th }}$ edition (DSM-IV, 2000).

\footnotetext{
${ }^{1}$ Department of Psychology, University of Hamadan

${ }^{2}$ Family Research Institute, Shahid Beheshti University University (mo_habibi@sbu.ac.ir)

${ }^{3}$ Department of Midwifery, Azad University of Arak

${ }^{4}$ Department of Clinical Psychology, University of Tehran, Tehran, Iran, (mani.b.monajemi@warwickgrad.net, mani.b.monajemi@ut.ac.ir)

(C) 2015 I N Zamani, M Habibi, N Zamani, N Jashidnejad, M B. Monajemi; licensee IJIP. This is an Open Access Research distributed under the terms of the Creative Commons Attribution License (http://creativecommons.org/licenses/by/2.0), which permits unrestricted use, distribution, and reproduction in any Medium, provided the original work is properly cited.
} 


\section{A Comparison between Personality Traits and Defense Styles in Teenagers with Avoidant Restrictive Food Intake Disorder and Normal Individuals}

People with this disorder restrict their food intake to the extent that the basic needs of body are not met and a lot of weight and energy is lost (Ganji,2013). This disorder occurs in children who avoid eating, merely because they want to win an argument or gain something (Zamani \& Habibi, 2014). People with this disorder may damage their health condition drastically due to their selective, choosy and restrictive eating habit (Ganji, 2013).

Avoiding food intake rarely occurs in normal situations and could be a big threat to health condition of the child but not as much as in ARFID (Zamani \& Habibi, 2014). This disorder is a deliberate behavior on the side of the child with the aim of controlling parents and it is also related to anxiety or depression (Ann, Sheri, \& Johnson, 2012).

DSM-V(2013) lists the following as the diagnostic criteria for ARFID: An eating or feeding disturbance (e.g., apparent lack of interest in eating or food avoidance based on sensory characteristics of food; concern about aversive consequences of eating) as manifested by persistent failure to meet appropriate nutritional and/or energy needs associated with significant weight loss, significant nutritional deficiency, dependence on enteral feeding or oral nutritional supplements and interference with psychosocial functioning. The disturbance is not better be explained by lack of available food or by associated culturally sanctioned practice.

One of the main issues concerning youth health is identity formation. Adolescence is usually said to begin from age 12-13 and to be continued until age 20 (Zamani et al., 2014). Adolescence is a period between childhood and adulthood; as adolescents in modern societies need to master a lot of developmental tasks and skills, this period lasts around ten years (Adrian, 2012). Developmental tasks of this period include acceptance of the rapid physical maturation, acquiring rational thinking abilities, reaching emotional and sometimes financial independency, learning appropriate communication skills with both sexes and most importantly, forming a coherent identity and gaining the sense of identity (Zamani et al., 2014).

Identity formation and acquiring appropriate skills to cope with the difficulties in the path of identity formation maintain a significant impact on teenagers' health and wellbeing (Jamilian et al., 2013). One of the ways to cope with identity formation, stress and anxiety is adoption of defense mechanisms.

Defense mechanisms are automatic regulation processes, which work to decrease the cognitive incongruity and minimize the drastic changes with respect to both inside and outside realities by altering the perception of threatening events (Vaillant, 2014). Coping techniques called defenses are various ways to cope with the natural discontentment in life and their adverse consequences; they may help people not to surrender to the situations (Holmens, 1994). In order to manage the challenges throughout life course, people tend to form defenses from early childhood (Fist\& Fist, 2012). 


\section{A Comparison between Personality Traits and Defense Styles in Teenagers with Avoidant Restrictive Food Intake Disorder and Normal Individuals}

Freud coined the concept of defense mechanisms in 1926 for the first time (Freud, 1905/1953) and his daughter Anna Freud improved the concept later on. Anna Freud brought about the first comprehensive and systematic study on defense mechanisms in her book The Ego and the Mechanisms of Defense in 1936 (Holmens, 1994). Although defense mechanisms are adaptive and everyone uses them, they could lead to obsessive compulsive and neurotic behavior if being used in extreme manner (Freud, 1905/1953). In psychoanalyst, each mental disorder is accompanied by certain maladaptive defense mechanisms (Bond \&Perry, 2004). Defenses play a significant role in people's mental health.

Freud considered personal defense style, which is the frequency of individual using defense mechanisms compared to others as the main factor in understanding the personality, psychopathology, and level of compromise. Various studies have confirmed this concept (Jamilian et al., 2013).

Empirical evidence shows that the defense mechanisms and styles could be organized hierarchically (Vaillantet al., 1999). A lot of maladaptive mechanisms and styles are related to the negative health measures, such as personality disorders and depression (Zamani et al., 2014).

Based on Vaillant's hierarchical categorization of defense mechanisms, the twenty mechanisms were divided into three categories of "mature", "immature", and "neurotic". Mature defence mechanisms are considered as adaptive and functional, while neurotic and immature defence mechanisms are maladaptive and dysfunctional coping methods (Vaillant, 2014).

When anxiety becomes overwhelming due to the unmet needs of id, that if met the person will have to face with the punishment from both the society and the conscience, defense mechanisms are employed. Defense mechanisms have some characteristics in common. For instance, most of the time they are applied unconsciously, and they are often accompanied by distortion, denial, and shift in reality and lead to self-deception. They all have a coping power and help the person to adapt unfavorable situations. Extreme use of defense mechanisms is a sign of the incompatibility of the personality (Freud, 1905/1953b).

All people use defense mechanisms and a moderate use of them could ease coping with difficult and stressful situation.

The use of defense mechanisms showsmaladaptation, when it happens constantly and in the absence of rational judgment. Studies show a relationship between immature and neurotic defence styles in adolescents (Jamilian et al., 2013) and assert that psychological variables that have an impact on adolescents' tendency towards the defense mechanisms are personality characteristics. The stress-diathesis theory shows how differences in characteristic, motivational, and environmental factors affect the personality. Due to lack of studies in comparing the defence 
mechanisms among teenagers with different personality traits, current study was conducted in order to compare personality traits and defense mechanisms in teenagers with ARFID and normal individuals.

\section{METHOD}

Current study is a fundamental research with the aim of explaining the relationship between events and adding to the existing knowledge in the field of defense mechanisms and because different groups are being compared, the overall design of the study is descriptive causalcomparative design. The population of the study is consisted of families of all individuals who had the inclusion criteria based on DSM-5. Sample of the study consisted of 220 teenagers with average age of $16.74 \pm 6.08$, who were selected by random sampling from among middle school and high school students with ARFID and 220 normal matched peers, in fall 2014. Three hundred girls and 140 boys were selected according to inclusion criteria: 1) Age range of 13-17 years, 2) No illness or eating disorder, 3) Diagnosis of ARFID.

\section{Questionnaires and measures:}

Andrews' Defense Style Questionnaire: This questionnaire was designed based on the hierarchical pattern of defense mechanisms with 88 items in order to examine 24 mechanisms and it empirically assesses the conscious aspects of defense styles in daily life (Andrews et al., 1993).

By the use of factor analysis methods, Bond and Colleagues(2004) introduced four defence styles of 1)maladaptive, 2) image-distorting, 3) self-sacrifice and 4) adaptive styles. Furthermore, they studied the relationship between the defense styles in four groups of psychopathologies and also studied a group of normal people. Results were not satisfactory; thus, Andrews and Colleagues (2007) used DSM III-R to design a 40-item questionnaire. This questionnaire assesses twenty defense mechanisms in three levels. Cronbach's alpha coefficient for the mature, immature, and neurotic mechanisms in the Persian form founded to be $0.75,0.73$, and 0.74 respectively among sample of students. That was $0.74,0.74$, and 0.72 among male students and $0.75,0.74$, and 0.74 among female students. This shows an adequate internal consistency of the Persian form of the Defense Style Questionnaire (Cramer, 2000).

Eysenck Personality Questionnaire: Eysenck Personality Questionnaire (EPQ) is a questionnaire, which assesses the personality traits of a person. Two forms of the questionnaire were designed; one for children between 7-15 years and another for 16 year olds and above. The latter form was used in the current study. This questionnaire contains ninety yes/no questions (Afzali et al., 2008). In order to determine the reliability and validity of the questionnaire, Eysenckcarried it out separately twice and calculated the validity and reliability. The internal validity coefficients (Cronbach's alpha) was $r=0.78$ for the men's psychoticismdimension, $r=0.90$ for extraversion, and $\mathrm{r}=0.88$ for Neuroticism. The numbers were respectively $\mathrm{r}=0.76, \mathrm{r}=0.85$, and $\mathrm{r}=0.85$ among women. According to $\mathrm{WHO}(2015)$, among Iranian population; results of the test- 
retest in two months period, were reported as $\mathrm{r}=0.72$ for psychoticism, $\mathrm{r}=0.92$ for extroversion, and $\mathrm{r}=0.89$ for neuroticism.

Both groups were asked to fill out Eysenck Personality Questionnaire and Andrews' Defence Style Questionnaire. Data was analyzed by the use of multivariate analysis of variance.

\section{RESULTS}

The descriptive statistics of the studied variables are presented in Table 1.

Table 1-Descriptive Statistics of the Studied Variables Separated by Groups

\begin{tabular}{|c|c|c|c|c|c|}
\hline Groups & Variables & & Mean & $\begin{array}{l}\text { Standard } \\
\text { Deviation }\end{array}$ & Number \\
\hline \multirow{6}{*}{$\begin{array}{r}\text { Defence } \\
\text { Styles }\end{array}$} & \multirow[t]{2}{*}{ Immature } & ARFID & 108.74 & 29.31 & 220 \\
\hline & & Normal & 78.35 & 28.09 & 220 \\
\hline & \multirow[t]{2}{*}{ Mature } & ARFID & 73.15 & 20.13 & 220 \\
\hline & & Normal & 95.08 & 24.24 & 220 \\
\hline & \multirow[t]{2}{*}{ Neurotic } & ARFID & 146.12 & 24.75 & 220 \\
\hline & & Normal & 74.01 & 20.79 & 220 \\
\hline \multirow{6}{*}{$\begin{array}{r}\text { Personality } \\
\text { Traits }\end{array}$} & \multirow[t]{2}{*}{ Psychoticism } & ARFID & 17.00 & 3.54 & 220 \\
\hline & & Normal & 12.07 & 4.44 & 220 \\
\hline & \multirow[t]{2}{*}{ Neuroticism } & ARFID & 21.19 & 5.69 & 220 \\
\hline & & Normal & 9.27 & 3.89 & 220 \\
\hline & \multirow[t]{2}{*}{ Extraversion } & ARFID & 19.19 & 5.57 & 220 \\
\hline & & Normal & 23.24 & 4.66 & 220 \\
\hline
\end{tabular}

In order to compare the defense mechanisms and personality traits in people with ARFID and normal people, multivariate analysis of variance was used. One of the preconditions of this analysis is the equality of the variance of errors. Levene's test result showed an equality between the variances and multivariate analysis of variance showed a significant difference $(\mathrm{P}<0.01$, $\mathrm{F}=7.25$, Wilks's lambda $=0.78$ ).

Table 2-Results of Multivariate Analysis of Variance for Comparing Defence Mechanisms and Personality Traits in the Two Groups

\begin{tabular}{rr|rr|r|r|r|}
\hline Variables & & $\begin{array}{r}\text { Sum of } \\
\text { Squares }\end{array}$ & $\begin{array}{r}\text { Degree of } \\
\text { Freedom }\end{array}$ & $\begin{array}{r}\text { Mean of } \\
\text { Squares }\end{array}$ & F & Significance \\
Defence & Immature & 387.87 & 1 & 387.87 & 5.87 & 0.089 \\
Styles & Mature & 135.09 & 1 & 135.09 & 4.84 & 0.065 \\
& Neurotic & 375.18 & 1 & 375.18 & 5.79 & 0.091 \\
& Psychoticism & 89.24 & 1 & 89.24 & 6.94 & 0.056 \\
Personality & Neuroticism & 98.87 & 1 & 98.87 & 7.25 & 0.054 \\
Traits & Extraversion & 76.81 & 1 & 76.81 & 8.29 & 0.067
\end{tabular}




\section{A Comparison between Personality Traits and Defense Styles in Teenagers with Avoidant Restrictive Food Intake Disorder and Normal Individuals}

As table 2 presents, there is a significant difference between the two groups in all the variables.

\section{DISCUSSION:}

The current study aims to compare the defence mechanisms and personality traits in teenagers with ARFID and normal teenagers. Results show that adolescents with ARFID use the immature and neurotic defense mechanisms more than the normal population. Defense mechanisms may have an important role in psychopathology and formation of different psychiatric disorders. According to the psychoanalytic theories, any type of psychopathology is marked with specific maladaptive defence mechanisms.

Freud's psychoanalytic theory had an enormous impact on both theory and practice of psychology and psychiatry, on our image of the nature of human beings, and on our understanding of personality (Afzali et al., 2008). Psychoanalytic models believe that people possess an inner world that has a strong influence on their thoughts, feelings, and behavior. Our inner world is formed by our feelings, memories, ideas, and fantasies (Baker, 1993). Freud believed in three levels of consciousness: conscious, subconscious, and unconscious (Green, 2003). The conscious mind works on the surface, beneath it is the subconscious, which has different depths. Having access to some of the information in the subconscious level is fairly easy. Unconscious is underneath the subconscious and is a storage for anxiety awakening information that are too distressing to enter consciousness such as sexual drives, anger, defense mechanisms, and some sensitive memories and feelings (Bond\& Perry, 2004).

People from their defences early in life, in order to manage the inevitable challenges of being human (Holmens, 1994). Thus, these defenses play an important role in personality formation. According to psychoanalyst theories, people use certain defense mechanisms when faced with stress. These styles are divided into four groups of immature, neurotic, narcissistic, and mature mechanisms (Vaillant, 1999). Each of these styles are linked to certain defense mechanisms. The quality of family and emotional relationships and the degree of vulnerability towards pressure, dramatically affect people's use of defense mechanisms.

Generally speaking, people with mental disorders use immature and maladaptive defence mechanisms compared to the normal population that adopt more mature mechanisms (Cramer, 2000). Although defense mechanisms are normal and almost everybody uses them, if used in excess they could lead to obsessive compulsive and neurotic behavior. Creation and maintenance of the defence mechanisms takes energy; hence, the more defensive people are, the less mental energy they have left for meeting impulses of the id. Ego is responsible in creating the defense mechanisms with the aim of avoiding a direct contact with instinctual desires and defending the self against anxiety (Freud, 1905/1953). Defense mechanisms distort the reality. The more immature and neurotic the defenses are, the more distortion they cause. The more a defense 


\section{A Comparison between Personality Traits and Defense Styles in Teenagers with Avoidant Restrictive Food Intake Disorder and Normal Individuals}

mechanism distorts reality, the less conscious it becomes and less effort is done to resist the cognitive distortion (Afzali et al., 2008).

Vaillant (1999) believes that the automatic defense mechanisms work to decrease the cognitive discordance and minimize sudden changes in the inner and outer reality, by affecting the perception of threatening events. According to him, if emotional and cognitive information are not processed and assessed correctly, one's system of affects and cognitions does not function correctly. Thus, the probability of using immature defense mechanisms increases in stressful circumstances. Because defense mechanisms alter our perception of self; hence, immature defense mechanisms may become a barrier in the way of people's perception of reality and interfere with their ability to defend themselves in a rational and effective manner and consequently it may decreases their insight capacity.

Basically, this study showed that the defense mechanism that is used most frequently by those with ARFID, is the neurotic defence mechanism and it is actually used twice as much compared to the normal population. These results are consistent with Nickel and Egle's(2006) study, investigating whether adolescents use these mechanisms more frequently or not. Jamilian and Colleagues (2013) showed that emotionally suffering people and those who are not pleased with their personality have high scores in reaction formation and undoing mechanisms that are also neurotic defense mechanisms.

Results also revealed that teenagers with ARRFID have the lowest scores in mature defence mechanisms. Mature defense mechanisms play a protective role for the self-esteem, while immature mechanisms by excessive distortion cause the ego to lose integration (Huang et al., 2006).

Furthermore, the results also showed that teenagers with avoidant ARFID get high scores in neuroticism. As Eysenck (1985) showed in his stress-diathesis theory, people with high scores in neuroticism answer to the environmental stressors with more severe emotional responses and higher levels of brain arousal. As a matter of fact, people with higher levels of neuroticism have less control on their impulses compared to others and cannot cope with stress effectively. Therefore, when they face the problems, instead of finding a solution to regulate their emotional state and reduce the perceived stress, they tend to show precarious behavior.

Studies show that neuroticism factor is a measure for emotional instability. Feelings like fear, sadness, irritation, anger, and guilt are bases of this measure. Presence of negative feelings has destructive impacts on people's adaptability. High scores in this item convey weak adaptive state, especially in high stress situations. Nonetheless, high score in this measure does not necessarily indicate a serious mental disorder (Ahmadi et al., 2012). Eysenck(1985) believes 
people with high scores in this measure could be described as nervous, moody, irritable, restless, agitated, irritable, depressed, anxious, shy, inflexible and with low self-esteem.

With respect to the limitations of the study difficulty in generalization can be noted. Due to relative lyheterogeneous sample (regarding ages) and also the random sampling method, the generalization of the results to other groups is difficult. Furthermore, ARFIDcan be discussed in different pathogenesis approaches with multiple causes; it is possible that in addition to individual issues, interpersonal and social factors, biological factor which were not focused on in the current study also contribute to its formation. As a result it is recommended that similar studies be done in different populations with regard to other risk factors in teenagers' personality formation. As most people with ARFID have deficits in problem-solving and coping skills, necessary measures should be taken in regards to educating people of these issues.

\section{Authors' contributions}

NZ and NZ conceived and designed the evaluation and they conducted whole process of this study. MBM and MH collected and interpreted the clinical data and drafted the manuscript. NJ Participated in conducting statistical evaluation. All authors read and approved the final manuscript.

\section{Acknowledgements}

We would like to thank all patients who participated in the study.

\section{Declaration of interest}

None declared

\section{REFERENCES}

Adrian W. (2012). Met cognitive therapy for anxiety and depression. Translated by M Akbari, A Mohammadee, Z Andooz.

Afzali M, Fathi-Ashtiani A, Azad Fallah P. (2008). Comparison of defence styles \& defence mechanisms of patients with obsessive-compulsive disorder \& normal people. J Hist Behav Sci; 2(3): 245-252. ]In Persian[

Ahmadi M, Najafi M, Hoseeni A, Ashiri A. (2012). Study of defensive methods and mechanisms in substance abuse. Quarterly Journal of Research on Addiction, Autumn 6 (23).

American Psychiatric Association, (2013). Diagnostic and Statistical Manual of Mental Disorders 5th edition, (Dsm-5).

American Psychiatric Association, Diagnostic and Statistical Manual of Mental Disorders 4 IV edition, (Dsm-4-IV); 2000.

Andrews G, Singh M., and Bond, M. (1993). The Defence style questionnaire. J NervMent Dis; 181 (4): 246-56. http://dx.doi.org/10.1097/00005053-199304000-00006

Ann M, Sheri L, Johnson L. (2012). Abnormal psychology, 12th Edition. 


\section{A Comparison between Personality Traits and Defense Styles in Teenagers with Avoidant Restrictive Food Intake Disorder and Normal Individuals}

Baker R. (1993). The patient's discovery of the psychoanalyst a new object, IntJ Psychoanal; 74:1223-33.

Besharat MA. (2007). Reliability and factorial validity of Farsi version of the Toronto alexithymia scale with a sample of Iranian students. Psycho Rep; 101: 209-20.

Bond M and Perry JC. (2004). Long-Term Changes in Defence Styles With Psychodynamic Psychotherapy for Depressive, Anxiety, and Personality Disorders. Am J Psychiatr; 161: 1665-1671.http://dx.doi.org/10.1176/appi.ajp.161.9.1665

Cramer P. (2000). Defence Mechanisms in Psychology Today. Am J Psychology;55(6):637646.http://dx.doi.org/10.1037/0003-066X.55.6.637

Eysenck HJ. (1985). Behaviorism and clinical psychiatry. International Journal of Social and Psychiatry; 31: 163-169.http://dx.doi.org/10.1177/002076408503100301

Fist J, Fist GJ. (2012). Personality theories translated by seydmohammadi. Tehran. Ravan publation.

Freud S. (1905/1953a). Three essays on the theory of sexuality. In Standard edition.

Freud S. (1905/1953b). Three essays on the theory of sexuality. In Standard edition.

Ganji M. (2013).Abnormal psychology based on DSM-5. Savalane pub. Tehran.

Green V. (2003). Emotional Development biological and clinical approaches. Towards an integration, in V. Green(ed), Emotional Divelopment in psychoanalysis, attachment Theory and Neuroscince. Hove: Brunner_Routiedge.

Holmens J. (1994). John Bowlby attachment Theory. London: Routiedge. ]In Persian[

Huang, B., Grant, B.F., Dawson, D.A., Stinson, F. S., Chou, S. P., Saha, T. D, Goldstein, R.

B., Smith, S. M., Ruan, W. J., Pickering, R. P. (2006). Race-ethnicity and the prevalenc and co occurrence of Diagnostic and Statistical Manual of Mental Disorders, FourthEdition, alcohol and drug use disorders and Axis I and II disorders: United States 200 0to 2002.Comprehensive $\quad$ Psychiatry, $47 \quad$ (4), 257.http://dx.doi.org/10.1016/j.comppsych.2005.11.001

JamilianH, Zamani N, Darvishi M \&Khansari M. (2013). Study of Defensive Methods and Mechanisms in Developmental,Emotional (Internalization), and Disruptive Behavior (Externalization) Disorders. Published by Canadian Centerof Science and Education, 6 (7). 109-115.

Nickel R, EgleUT. (2006). Psychological defence styles, childhood adversities andpsychopathology in adulthood. Child Abuse \& Neglect, 30(2), 15770.http://dx.doi.org/10.1016/j.chiabu.2005.08.016

Sen martini P, Roma R, Sarti S, Lingiardi V and Bond M. (2004). Italian vertion of the Defence Styles Questionnaire. Compr Psychiatr; 45(6): 483-494. http://dx.doi.org/10.1016/j.comppsych.2004.07.012

Vaillant GE. (2014). Adaptation to life. Cambridge, MA: Harvard University Press.

VaillantG E. (1999). Ego Mechanisms of Defence: A Guide for Clinicians and Researchers, Washington, DC, American Psychiatric Press. 


\section{A Comparison between Personality Traits and Defense Styles in Teenagers with Avoidant Restrictive Food Intake Disorder and Normal Individuals}

Vaillant GE, Vaillant CO. (2010).Natural history of male psychological health, XXII: year study of predictors of successful aging at age65. American Journal ofPsychiatry,147, 31-37.

World Health Organization. (2015). Suicide rates. http://www. who. int/mental _health/ prevention/ suicide/suicide rates/en.

Zamani N, Ahmadi V, Ataie Moghanloo V, Mirshekar S. (2014). Comparing the effectiveness of two therapeutic methods: Dialectical behavioral therapy and cognitive behavior therapy on the improvement of impulsive behavior in the patients suffering from major depressive disorder who are showing a tendency to suicide. Journal of Ilam University of Medical Sciences. 22(25); 45-54.

Zamani N, Darvishi M, Habibi M. (2014). Relationship between meta-cognition with anxiety and depression in Mothers of children with mental disorders. Accepted in Journal of Research \& Health Social Development \& Health Promotion Research Center.

Zamani N, Habibi M. (2014). compare the influence of both dialectic and cognitive behavior therapies to maintain mothers' mental health whose children with Special needs. Accepted in Journal of Research \& Health Social Development \& Health Promotion Research Center. [Persian]

Zamani N, Habibi M, Darvishi M. (2014). Compare the effectiveness dialectical behavior therapy and cognitive-behavioral group therapy in reducing depression in mothers of children with disabilities Accepted in Journal of Arak University of Medical Sciences. 